\title{
Trail Making Test: Normative data for the Latin American Spanish-speaking pediatric population
}

J.C. Arango-Lasprilla ${ }^{\mathrm{a}, \mathrm{b}, *}$, D. Rivera ${ }^{\mathrm{b}}$, D. Ramos-Usuga ${ }^{\mathrm{c}}$, E. Vergara-Moragues $^{\mathrm{d}}$, E. Montero-López $^{\mathrm{e}}$, L.A. Adana Díaz ${ }^{f}$, A. Aguayo Arelis ${ }^{g}$, C.E. García-Guerrero ${ }^{h}$, C. García de la Cadena ${ }^{\mathrm{i}}$, X. Llerena Espezúa ${ }^{j}$, L. Lara ${ }^{\mathrm{k}}$, A. Padilla-López ${ }^{1}$, W. Rodriguez-Irizarry ${ }^{\mathrm{m}}$, C. Alcazar Tebar ${ }^{\mathrm{c}}$, M.J. Irías Escher ${ }^{\mathrm{n}}$, J.J. Llibre Guerra ${ }^{ }$, N. Torales Cabrera ${ }^{\mathrm{p}}$, Y. Rodríguez-Agudelo ${ }^{\mathrm{q}}$ and R. Ferrer-Cascales ${ }^{\mathrm{r}}$

a IKERBASQUE, Basque Foundation for Science, Bilbao, Spain

${ }^{\mathrm{b}}$ BioCruces Health Research Institute, Cruces University Hospital, Barakaldo, Spain

${ }^{\mathrm{c}}$ Research Center CERNEP, Almeria University, Almería, Spain

${ }^{\mathrm{d}}$ Universidad Internacional de la Rioja (UNIR), Logroño, Spain

${ }^{\mathrm{e}}$ CIMCYC-The Mind, Brain and Behaviour Research Centre, Universidad de Granada, Granada, Spain

${ }^{\mathrm{f}}$ Escuela de Psicología, Universidad de Las Américas, Quito, Ecuador

gepartamento de investigación, Psicología, Universidad Enrique Díaz de León., Guadalajara, Mexico

${ }^{\mathrm{h}}$ Mindpedia Centro de Psicología Avanzada, Monterrey, México

${ }^{\mathrm{i}}$ Departamento de Psicología, Universidad del Valle de Guatemala, Guatemala City, Guatemala

${ }^{\text {j}}$ Universidad Católica San Pablo, Arequipa, Perú

${ }^{\mathrm{k}}$ Universidad Autónoma de Chile, Talca, Chile

${ }^{1}$ Laboratorio de Psicofisiología, Facultad de Ciencias Humanas, Universidad Autónoma de Baja California, Mexicali, México

${ }^{\mathrm{m}}$ Universidad Interamericana de Puerto Rico, Recinto de San Germán, Puerto Rico

${ }^{\mathrm{n}}$ Escuela de Ciencias Psicológicas., Universidad Nacional Autónoma de Honduras, Tegucigalpa, Honduras

${ }^{\circ}$ National Institute of Neurology and Neurosurgery INN, Havana, Cuba

${ }^{\mathrm{p}}$ Universidad Autónoma de Asunción (UAA), Asunción, Paraguay

${ }^{\mathrm{q}}$ Instituto Nacional de Neurología y Neurocirugía, MVS, Ciudad de México, Mexico

${ }^{\mathrm{r}}$ Department of Health Psychology, University of Alicante, Spain

\begin{abstract}
.
OBJECTIVE: To generate normative data for the Trail Making Test (TMT) in Spanish-speaking pediatric populations. METHOD: The sample consisted of 3,337 healthy children from nine countries in Latin America (Chile, Cuba, Ecuador, Guatemala, Honduras, Mexico, Paraguay, Peru, and Puerto Rico) and Spain. Each participant was administered the TMT as part of a larger neuropsychological battery. The TMT-A and TMT-B scores were normed using multiple linear regressions and standard deviations of residual values. Age, age ${ }^{2}$, sex, and mean level of parental education (MLPE) were included as predictors in the analyses.
\end{abstract}

*Address for correspondence: Juan Carlos Arango-Lasprilla, Ph.D., BioCruces Health Research Institute., Cruces University Hospital, IKERBASQUE., Basque Foundation for Science, Plaza de Cruces s/n. 48903, Barakaldo., Bizkaia, Spain. Tel.: +34 946006000/Ext. 7963; E-mail: jcalasprilla@gmail.com. 
RESULTS: The final multiple linear regression models showed main effects for age on both scores, such that as children needed less time to complete the test while they become older. TMT-A scores were affected by age ${ }^{2}$ for all countries except, Cuba, Guatemala, and Puerto. TMT-B scores were affected by age ${ }^{2}$ for all countries except, Guatemala and Puerto Rico. Models indicated that children whose parent(s) had a MLPE $>12$ years of education needed less time to complete the test compared to children whose parent(s) had a MLPE $\leq 12$ years for Mexico and Paraguay in TMT-A scores; and Ecuador, Mexico, Paraguay, and Spain for TMT-B scores. Sex affected TMT-A scores for Chile, Cuba, Mexico, and Peru, in that boys needed less time to complete the test than girls. Sex did not affect TMT-B scores.

CONCLUSIONS: This is the largest Spanish-speaking pediatric normative study in the world, and it will allow neuropsychologists from these countries to have a more accurate approach to interpret the TMT in pediatric populations.

Keywords: Trail Making Test, neuropsychology, Spanish-speaking populations, pediatric population

\section{Introduction}

Given that both attention span and executive functions (EF) are developed throughout infancy and adolescence and play an essential role in the child's cognitive, behavioral, emotional, and social functioning (Anderson, 2002), it is of paramount importance to have adequate tools to evaluate the functioning of these cognitive processes. In this respect, numerous neuropsychological tests have been developed during the last decades. The Trail Making Test (TMT) is one of the most used in clinical and research work (Rabin, Barr, \& Burton, 2005; Strauss, Sherman, \& Spreen, 2006). This instrument was originally designed by Partington as a measure of divided attention, and included in the "Leiter-Partington Adult Performance Scale" under the name "Partington's Pathways Test" (Partington \& Leiter, 1949). It later became part of the Army Individual Test of General Ability and was renamed as it is currently known (Adjutant General's Office, 1944). Finally, after a few modifications, it was incorporated into the Halstead-Reitan Neuropsychological Battery for the purpose of detecting brain damage (Reitan, 1958; Reitan, 1979).

TMT has been shown to be a useful instrument for measuring not only attention and EF, but also speed and visual-motor coordination (Fernández, Marino, \& Alderete, 2002; Lezak, 1995; Tombaugh, 2004). It consists of two parts in which the goal is to connect, as fast as possible and without lifting the pencil from the sheet, a series of randomly distributed circles. In part $\mathrm{A}$, the circles contain 25 numbers that must be joined up (1-2-3 ...), while in part B, 13 numbers and 12 letters must be alternated in ascending order (1-A, 2-B, 3-C ... ). The examiner must stop the test every time an error is made, and start again from the last circle correctly matched. The latency, including the time taken for correction (Reitan, 1992), is measured, with the time limit for TMT-A being 100 seconds, and 300 seconds for TMT-B (Arango-Lasprilla et al., 2015b). Moreover, derived scores can be obtained (the difference $\mathrm{B}-\mathrm{A}$, and the $\mathrm{B}$ : A ratio) that allow the evaluation of EF independently, eliminating the velocity component (Sanchez-Cubillo et al., 2009).

This original version is the one that is commonly used, regardless of age or culture. However, there are children's versions of the test more suitable for children, considering that the ability of children, especially at younger ages, differ greatly from that of adults. In fact, Mateo (2010) carried out a study which aimed to assess whether the adult TMT was appropriate for the child population. Since most of the children could not complete it, it was concluded that this test is too complex for children under 12 years old. For this reason, it is necessary to reiterate the need to use the following TMT versions with this population.

Reitan (1958) first developed a version for children under 15, which has the same characteristics as that of adults, and only differs in the number of stimuli presented. Thus, the 25 numbers in part $A$ are reduced to 15 , and the 13 numbers and 12 letters in part $B$ are replaced by 8 and 7 elements, respectively.

Second, considering that preschool children have less manual skills, variable attention spans and more limited linguistic abilities to understand instructions, Espy and Cwik (2004) designed the TRAILS-P. The stimuli, in this case, are puppies of different sizes that the child must stamp with a seal, from the smallest to the largest. The equivalent condition for part B is to alternately stamp the puppies and the same size bones. In parts $C$ and $D$, in turn, the child must perform the same task as in A, but ignoring the bones in the $\mathrm{C}$ and the cats in the $\mathrm{D}$, which are presented as distracting stimuli.

Thirdly, there is the Llorente Children's Color Trails Test (2003) which consists of two parts in which a series of numbered circles are to be matched. The first part is exactly the same as the TMT, in the second, the circles are colored, and the matching 
of the numbers must be done alternating the colors pink and yellow (Blanco-Gómez et al., 2015). The substitution of letters for colors minimizes the influence of culture and language (Williams et al., 1995), which is extremely useful when evaluating children with reading problems (Närhi, Räsänen, Metsäpelto, \& Ahonen, 1997; Reitan \& Boll, 1973; Reitan \& Wolfson, 1988, 1992).

Finally, there is Reynolds' Comprehensive Trail Making Test (2002), a more extensive adaptation of the original, developed in order to more comprehensively evaluate EF. It consists of five parts, the first being identical to part A of the TMT. In the second and third parts, in addition to the numbered circles, there are included distracting stimuli: 29 empty circles in the second, and 13 empty circles and another 19 circles with a line inside the third. In the fourth, there are 20 numbers that have to be joined [11 Arabic numerals ("1") and nine written words ("two")]. Finally, the fifth part is similar to TMT B, but with the added difficulty of 15 empty circles as distractors.

As for the variables associated with children's performance on the test, the most influential factors are age and schooling (Beltrán Dulcey \& Solís-Uribe, 2012; Lee, Yuen, \& Chan, 2002; Lee, Wallace, Raznahan, Clasen, \& Giedd, 2014; Periáñez et al., 2007; Zalonis et al., 2008), so that older children and those with more schooling obtain better results. Regarding gender, there are studies that have shown significant differences (Lee et al., 2002), while others have not found any influence (Beltrán Dulcey \& SolísUribe, 2012; León-Carrión, 1989; Mok, Tsang, Lee, $\&$ Llorente, 2008). Finally, although the influence of parental education on children's performance in TMT has not been studied, Van der Elst, Hurks, Wassenberg, Meijs, and Jolles (2011) have shown that high parental schooling correlates with better child performance on verbal fluency tests, so it would be advisable to include this variable in future research concerning the neuropsychological performance of children.

Different studies agree that TMT is one of the most used tests by neuropsychologists worldwide. This is shown by the high use of the instrument in countries of Latin America (Arango-Lasprilla et al., 2015a; Arango-Lasprilla, Stevens, Morlett-Paredes, Ardila, \& Rivera, 2016; Fernández, Ferreres, MorlettParedes, Rivera, \& Arango-Lasprilla, 2016), North America (Rabin et al., 2005), Spain (OlabarrietaLanda et al., 2016) and the Nordic countries (Egeland et al., 2016). Despite its widespread use, the problem lies in the lack of normative data. The majority of studies focus on the adult population in countries such as Japan (Abe et al., 2004; Hashimoto et al., 2006), Korea (Seo et al., 2006), Spain (Peña-Casanova et al., 2009), Turkey (Cangoz, Karakoc, \& Selekler, 2009), China (Wang et al., 2011), Czech Republic (Bezdicek, 2012) Portugal (Cavaco et al., 2013) and Latin America (Arango-Lasprilla et al., 2015b).

Even in the few attempts to conduct general population studies including a younger sample, only teenagers have been included. For example, in China (Lee et al., 2002) the mean age was 14.5 years and in Germany (Zalonis et al., 2008) the youngest age range was 16 to 19 years. As for the Spanish-speaking countries, three normative studies have been carried out, one in Argentina (Fernández et al., 2002), including adolescents over 15 years old and two in Spain, the first (León-Carrión, 1989) with children aged 10 to 15 and the second (Periáñez et al., 2007), as well as in Argentina with adolescents over 15 years old.

In conclusion, the lack of normative data in children is global, and although in Spanish-speaking countries there are studies for two countries (Argentina and Spain), their limitations are evident: 1) children's versions are not used, 2) the age range is very limited, excluding primary school children, 3 ) the samples are small, and 4) the studies were conducted many years ago. It is for this reason that the objective of this study is to obtain normative data for children and adolescents from nine Latin American countries (Chile, Cuba, Ecuador, Guatemala, Honduras, Mexico, Paraguay, Peru, and Puerto Rico) and Spain based on multiple linear regressions.

\section{Method}

\subsection{Participants}

The sample consisted of 3,337 healthy children who were recruited from Chile, Cuba, Ecuador, Guatemala, Honduras, Mexico, Paraguay, Peru, Puerto Rico, and Spain. Participants were selected according to the following criteria: a) were between 6 and 14 years of age, b) were born and currently lived in a country where the study was conducted, c) spoke Spanish as their mother tongue, d) an IQ $\geq 80$ on the Test Of Non-verbal Intelligence (TONI-2, Brown, Sherbenou, \& Johnsen, 2009), and e) scored $<19$ on the Children's Depression Inventory (CDI, Kovacs, 1992).

Children with history of neurologic or psychiatric disorders as reported by the participant's parent(s) 
Table 1

Sample distribution by age, sex and MLPE

\begin{tabular}{|c|c|c|c|c|c|}
\hline & \multirow[t]{3}{*}{$n$ Total } & \multirow{3}{*}{$\frac{\text { Age }}{\text { Mean }(\mathrm{SD})}$} & \multicolumn{2}{|c|}{ Sex } & \multirow{3}{*}{$\frac{\text { MLPE }}{\text { Mean (SD) }}$} \\
\hline & & & Girls & Boys & \\
\hline & & & $n(\%)$ & $n(\%)$ & \\
\hline Chile & 289 & $10.0(2.6)$ & $145(50.2 \%)$ & $144(49.8 \%)$ & $\overline{12.5(3.0)}$ \\
\hline Cuba & 286 & $10.0(2.6)$ & $142(49.7 \%)$ & $144(50.3 \%)$ & $16.1(1.8)$ \\
\hline Ecuador & 230 & $9.9(2.6)$ & $134(58.3 \%)$ & $96(41.7 \%)$ & $14.4(3.6)$ \\
\hline Guatemala & 181 & $10.1(1.9)$ & $79(43.9 \%)$ & $101(56.1 \%)$ & $10.0(3.9)$ \\
\hline Honduras & 244 & $10.0(2.5)$ & $128(52.2 \%)$ & $116(47.5 \%)$ & $12.6(3.7)$ \\
\hline Mexico & 707 & $9.9(2.6)$ & $362(51.2 \%)$ & $345(48.8 \%)$ & $13.4(4.0)$ \\
\hline Paraguay & 214 & $9.9(2.5)$ & $120(56.1 \%)$ & $94(43.9 \%)$ & $14.1(2.9)$ \\
\hline Peru & 254 & $10.5(2.6)$ & $118(46.5 \%)$ & $136(53.5 \%)$ & $12.4(2.4)$ \\
\hline Puerto Rico & 148 & $10.4(2.8)$ & $84(56.8 \%)$ & $64(43.2 \%)$ & $14.7(2.5)$ \\
\hline Spain & 784 & $10.0(2.5)$ & $397(50.6 \%)$ & $387(49.4 \%)$ & $14.2(4.0)$ \\
\hline
\end{tabular}

Note. MLPE: Mean level of parental education.

were excluded due to its effects on cognitive performance. Participants in the study were from public and private schools, and signed an informed consent. Table 1 presents socio-demographic and participant characteristics for each country. Ethics Committee approval was obtained for the study in each country.

\subsection{Instrument administration}

The Trail Making Test (TMT) provides information on visual attention, motor speed, cognitive flexibility and task alternation (Tombaugh, 2004). The test consists of two parts in which the task is to connect randomly distributed points. In part A, all objectives are numbers ( 1 to 15 ) and the participant must join them up (1-2-3 ..), while in part $\mathrm{B}$, must alternate between numbers and letters of the next lever (1-A, 2-B, 3-C...). The total score is the number of seconds that the participant needs to complete the task (Reitan, 1992), with a time limit of 60 and 150 seconds for TMT-A and TMT-B, respectively.

\subsection{Statistical analyses}

Detailed statistical analyses used to generate the normative data for the TMT-A and TMT-B scores (measured in time) are described in Rivera \& Arango-Lasprilla (2017). In summary, the scores were standardized using multiple linear regression analyses by means of a four-step procedure. 1) First, the TMT-A and TMT-B scores were computed separately by means of the final multiple regression models. The full regression models included as pre- dictors: age, age $^{2}$, sex, and mean level of parental education (MLPE). Age was centered (= calendar age - mean age in the sample by country) before computing the quadratic age term to avoid multicollinearity (Aiken \& West, 1991). Sex was coded as male $=1$ and female $=0$. The MLPE variable was coded as 1 if the participant's parent(s) had $>12$ years of education or 0 if participant's parent(s) had $\leq 12$ years of education. If predicted variables were not statistically significant in the multivariate model with an alpha of 0.05 , the non-significant variables were removed and the model was run again. A final regression model was conducted $\hat{y}_{i}=\mathrm{B}_{0}+\mathrm{B}_{1} \cdot\left(\text { Age }-\bar{x}_{\text {Age by country }}\right)_{i}+\mathrm{B}_{2}$. $\left.\left(\text { Age }-\bar{x}_{\text {Age by country }}\right)_{i}^{2}+\mathrm{B}_{3} \cdot \operatorname{Sex}_{i}+\mathrm{B}_{4} \cdot M L P E_{i} \cdot 2\right)$ Residual scores were calculated based on the final model $\left.\left(e_{i}=y_{i}-\hat{y}_{i}\right) .3\right)$ Residuals were standardized using the residual Standard Deviation $\left(S D_{e}\right)$ value provided by the regression model: $z_{i}=e_{i} / S D_{e}$. 4) Standardized residuals were converted to percentile values using the standard normal cumulative distribution function. This four-step process was applied for TMT-A and TMT-B scores separately for each country.

For all multiple linear regression models, the following assumptions were evaluated: a) multicollinearity by the values of the Variance Inflation Factor (VIF), which must not exceed 10, and the collinearity tolerance values, which must not exceed the value of 1 (Kutner, Nachtsheim, Neter, \& Li, 2005), and b) the existence of influential values by calculating the Cook's distance. The maximum Cook's distance value was related to a $F(p, n-p)$ distribution. Influential values are considered when percentile value is equal or higher than 50 (Cook, 1977; Kutner et al., 2005). All analyzes were 
performed using SPSS version 23 (IBM Corp., Armonk, NY).

\section{Results}

\subsection{TMT-A}

The final multivariate linear regression models for the ten country-specific TMT-A scores were significant (see Table 2). In all countries, the TMT-A scores were affected by age so that children needed less time to complete the test while they become older. The TMT-A score for all countries except, Cuba, Guatemala, and Puerto Rico was affected by a quadratic age effect. Children from Mexico and Paraguay whose parent(s) had a MLPE $>12$ years of education needed less time to complete TMT-A test than children whose parent(s) had a MLPE $\leq 12$ years. The child's sex affected TMT-A score for Chile, Cuba, Mexico, and Peru, such that boys needed less time to complete the task than girls. The amount of variance these predictors explained in the TMT-A score ranged from $11.4 \%$ (in Cuba) to $39.4 \%$ (in Ecuador).

Table 2

Final multiple linear regression models for TMT-A

\begin{tabular}{|c|c|c|c|c|c|c|}
\hline Country & $\mathrm{B}$ & Std. Error & $t$ & Sig. & $R^{2}$ & $S D e$ (residual) \\
\hline \multicolumn{7}{|l|}{ Chile } \\
\hline Constant & 30.604 & 1.187 & 25.790 & $<0.001$ & 0.328 & 11.141 \\
\hline Age & -2.888 & 0.257 & -11.251 & $<0.001$ & & \\
\hline $\mathrm{Age}^{2}$ & 0.247 & 0.113 & 2.188 & 0.030 & & \\
\hline Sex & -3.418 & 1.320 & -2.589 & 0.010 & & \\
\hline \multicolumn{7}{|l|}{ Cuba } \\
\hline Constant & 36.358 & 1.026 & 35.443 & $<0.001$ & 0.114 & 12.138 \\
\hline Age & -1.490 & 0.279 & -5.349 & $<0.001$ & & \\
\hline Sex & -4.011 & 1.443 & -2.779 & 0.006 & & \\
\hline \multicolumn{7}{|l|}{ Ecuador } \\
\hline Constant & 30.956 & 1.108 & 27.949 & $<0.001$ & 0.394 & 10.794 \\
\hline Age & -3.418 & 0.283 & -12.084 & $<0.001$ & & \\
\hline $\mathrm{Age}^{2}$ & 0.218 & 0.131 & 1.664 & 0.097 & & \\
\hline \multicolumn{7}{|l|}{ Guatemala } \\
\hline Constant & 29.845 & 0.754 & 39.568 & $<0.001$ & 0.134 & 10.119 \\
\hline Age & -2.077 & 0.394 & -5.273 & $<0.001$ & & \\
\hline \multicolumn{7}{|l|}{ Honduras } \\
\hline Constant & 29.356 & 1.052 & 27.903 & $<0.001$ & 0.238 & 11.242 \\
\hline Age & -2.391 & 0.298 & -8.021 & $<0.001$ & & \\
\hline $\mathrm{Age}^{2}$ & 0.484 & 0.126 & 3.844 & $<0.001$ & & \\
\hline \multicolumn{7}{|l|}{ Mexico } \\
\hline Constant & 33.017 & 0.908 & 36.374 & $<0.001$ & 0.295 & 11.426 \\
\hline Age & -2.564 & 0.167 & -15.375 & $<0.001$ & & \\
\hline $\mathrm{Age}^{2}$ & 0.302 & 0.073 & 4.113 & $<0.001$ & & \\
\hline MLPE & -4.139 & 0.876 & -4.725 & $<0.001$ & & \\
\hline Sex & -2.305 & 0.870 & -2.650 & 0.008 & & \\
\hline \multicolumn{7}{|l|}{ Paraguay } \\
\hline Constant & 37.647 & 1.724 & 21.837 & $<0.001$ & 0.295 & 12.657 \\
\hline Age & -2.963 & 0.350 & -8.457 & $<0.001$ & & \\
\hline $\mathrm{Age}^{2}$ & 0.388 & 0.153 & 2.545 & 0.012 & & \\
\hline MLPE & -6.212 & 1.814 & -3.424 & 0.001 & & \\
\hline \multicolumn{7}{|l|}{ Peru } \\
\hline Constant & 28.479 & 1.431 & 19.906 & $<0.001$ & 0.137 & 11.798 \\
\hline Age & -1.190 & 0.299 & -3.974 & $<0.001$ & & \\
\hline $\mathrm{Age}^{2}$ & 0.447 & 0.132 & 3.385 & 0.001 & & \\
\hline Sex & -3.016 & 1.511 & -1.996 & 0.047 & & \\
\hline \multicolumn{7}{|l|}{ Puerto Rico } \\
\hline Constant & 30.383 & 1.127 & 26.958 & $<0.001$ & 0.207 & 13.191 \\
\hline Age & -2.347 & 0.394 & -5.957 & $<0.001$ & & \\
\hline \multicolumn{7}{|l|}{ Spain } \\
\hline Constant & 22.844 & 0.497 & 45.922 & $<0.001$ & 0.383 & 9.297 \\
\hline Age & -2.809 & 0.132 & -21.204 & $<0.001$ & & \\
\hline $\mathrm{Age}^{2}$ & 0.297 & 0.058 & 5.073 & $<0.001$ & & \\
\hline
\end{tabular}

Note. MLPE: Mean level of parental education. 


\section{2. $T M T-B$}

The final multivariate linear regression models for the ten country-specific TMT-B scores were significant (see Table 3). TMT-B scores were affected by age so that children needed less time to complete the test while they become older. The TMT-B scores for all countries except for Guatemala and Puerto Rico were affected by a quadratic age effect. Children from Ecuador, Mexico, Paraguay, and Spain whose parents had a MLPE $>12$ years of education needed less time to complete TMT-B test than children whose par- ents had a MLPE $\leq 12$ years of education. The child's sex did not affect TMT-B score for any country. The amount of variance these predictors explained in the TMT-B scores ranged from $8.9 \%$ (in Cuba) to $48.6 \%$ (in Spain).

The assumptions of multiple linear regression analysis were met for all final models. There was not multicollinearity (the VIF values were below 10; VIF $\leq 1.051$; collinearity tolerance values did not exceed the value of 1) or influential cases (the maximum Cook's distance value was 0.094 in a $F_{(2,146)}$ distribution which correspond to percentile 9 ).

Table 3

Final multiple linear regression models for TMT-B

\begin{tabular}{|c|c|c|c|c|c|c|}
\hline Country & $\mathrm{B}$ & Std. Error & $t$ & Sig. & $R^{2}$ & $S D e$ (residual) \\
\hline \multicolumn{7}{|l|}{ Chile } \\
\hline Constant & 54.709 & 2.397 & 22.825 & $<0.001$ & \multirow[t]{3}{*}{0.387} & \multirow[t]{3}{*}{26.856} \\
\hline Age & -7.917 & 0.621 & -12.753 & $<0.001$ & & \\
\hline $\mathrm{Age}^{2}$ & 1.103 & 0.273 & 4.041 & $<0.001$ & & \\
\hline \multicolumn{7}{|l|}{ Cuba } \\
\hline Constant & 67.188 & 2.798 & 24.010 & $<0.001$ & \multirow[t]{3}{*}{0.089} & \multirow[t]{3}{*}{30.961} \\
\hline Age & -1.649 & 0.709 & -2.326 & 0.021 & & \\
\hline $\mathrm{Age}^{2}$ & 1.488 & 0.314 & 4.734 & $<0.001$ & & \\
\hline \multicolumn{7}{|l|}{ Ecuador } \\
\hline Constant & 56.861 & 3.274 & 17.365 & $<0.001$ & \multirow[t]{4}{*}{0.477} & \multirow[t]{4}{*}{21.880} \\
\hline Age & -7.972 & 0.577 & -13.805 & $<0.001$ & & \\
\hline $\mathrm{Age}^{2}$ & 1.212 & 0.268 & 4.518 & $<0.001$ & & \\
\hline MLPE & -7.830 & 3.348 & -2.339 & 0.020 & & \\
\hline \multicolumn{7}{|l|}{ Guatemala } \\
\hline Constant & 57.064 & 1.575 & 36.224 & $<0.001$ & \multirow[t]{2}{*}{0.269} & \multirow[t]{2}{*}{21.135} \\
\hline Age & -6.671 & 0.823 & -8.109 & $<0.001$ & & \\
\hline \multicolumn{7}{|l|}{ Honduras } \\
\hline Constant & 58.555 & 2.750 & 21.289 & $<0.001$ & \multirow[t]{3}{*}{0.211} & \multirow[t]{3}{*}{21.135} \\
\hline Age & -5.906 & 0.779 & -7.578 & $<0.001$ & & \\
\hline $\mathrm{Age}^{2}$ & 1.040 & 0.329 & 3.157 & 0.002 & & \\
\hline \multicolumn{7}{|l|}{ Mexico } \\
\hline Constant & 64.023 & 2.135 & 29.986 & $<0.001$ & \multirow[t]{4}{*}{0.334} & \multirow[t]{4}{*}{30.036} \\
\hline Age & -7.584 & 0.448 & -16.939 & $<0.001$ & & \\
\hline $\mathrm{Age}^{2}$ & 1.110 & 0.196 & 5.655 & $<0.001$ & & \\
\hline MLPE & -11.132 & 2.323 & -4.793 & $<0.001$ & & \\
\hline \multicolumn{7}{|l|}{ Paraguay } \\
\hline Constant & 71.830 & 3.656 & 19.648 & $<0.001$ & \multirow[t]{4}{*}{0.338} & \multirow[t]{4}{*}{21.135} \\
\hline Age & -7.226 & 0.752 & -9.611 & $<0.001$ & & \\
\hline $\mathrm{Age}^{2}$ & 0.963 & 0.327 & 2.940 & 0.004 & & \\
\hline MLPE & -11.628 & 3.858 & -3.014 & 0.003 & & \\
\hline \multicolumn{7}{|l|}{ Peru } \\
\hline Constant & 51.024 & 2.736 & 18.647 & $<0.001$ & \multirow[t]{3}{*}{0.225} & \multirow[t]{3}{*}{28.141} \\
\hline Age & -4.232 & 0.712 & -5.942 & $<0.001$ & & \\
\hline $\mathrm{Age}^{2}$ & 1.443 & 0.314 & 4.601 & $<0.001$ & & \\
\hline Puerto Rico & & & & & & \\
\hline Constant & 58.643 & 2.469 & 23.756 & $<0.001$ & 0.149 & 29.101 \\
\hline Age & -4.236 & 0.863 & -4.911 & $<0.001$ & & \\
\hline Spain & & & & & & \\
\hline Constant & 44.166 & 1.541 & 28.663 & $<0.001$ & 0.486 & 20.634 \\
\hline Age & -7.377 & 0.298 & -24.776 & $<0.001$ & & \\
\hline $\mathrm{Age}^{2}$ & 1.247 & 0.131 & 9.495 & $<0.001$ & & \\
\hline MLPE & -3.622 & 1.572 & -2.305 & 0.021 & & \\
\hline
\end{tabular}

Note. MLPE: Mean level of parental education. 


\subsection{Normative procedure}

Norms (e.g., a percentile score) for the different TMT scores by country were established using the four-step procedure described in the statistical analysis section. An example will be provided to facilitate an improved understanding of the procedure used to obtain the percentile associated with a score on this test. Let's assume we need to find the percentile score for a 7-year-old Peruvian girl who scored 30 seconds on the TMT-A and whose parent(s) have a mean of 12 years of education (MLPE). The steps to obtain the percentile for this score are: 1) Find Peru in Table 2, which provides the final regression models by country for the TMT-A scores. Use the $\mathrm{B}$ weights to create an equation that will allow you to obtain the predicted TMT-A score for this child using the coding provided in the statistical analysis section. The corresponding B weights are multiplied by the centered age (=calendar age - mean age in the Peruvian sample which is equal to 10.5 years), centered age ${ }^{2}$ (= calendar age - mean age in the Peruvian sample which is equal to 10.5 years $)^{2}$, and sex, which was coded as male $=1$ and female $=0$. MLPE was not a significant predictor, and therefore is not included in this model. See Table 1 the mean age of each country's sample. Finally, the result is added to the constant generated by the model in order to calculate the predicted value.

In the case of the Peruvian girl, the predicted TMTA score would be calculated using the following equation: $\hat{y}_{i}=28.479+\left[-1.190 \cdot\left(\mathrm{Age}_{i}-10.5\right)\right]+$ $\left[0.447 \cdot\left(\text { Age }_{i}-10.5\right)^{2}\right]+[(-3.016) \cdot$ Sex $] . \quad$ The girl's age is 7 . Sex was coded as male $=1$ and female $=0$, so in this case as the child is a female, the sex value is 0 . Thus, the predicted value equation is: $\quad \hat{y}_{i}=28.479+[-1.190 \cdot(7-10.5)]+$ $\left.\left[0.447 \cdot(7-10.5)^{2}\right]+(-3.016 \cdot 0)=38.116 .2\right)$ In order to calculate the residual value (indicated with an $e_{i}$ in the equation), we subtract the actual TMT-A score (she scored 30) from the predicted value we just calculated $\left(e_{i}=y_{i}-\hat{y}_{i}\right)$. In this case, it would be $e_{i}=30-38.116=-8.116$. 3) Next, consult the $S D_{e}$ column in Table 2 to obtain the country-specific $S D_{e}$ (residual) value. For Peru it is 11.798. Using this value, we can transform the residual value to a standardized $z$ score using the equation $z_{i}=e_{i} / S D_{e}$. In this case, we have $-8.116 / 11.798=-0.688$. This is the standardized $z$ score for a 7 -year-old Peruvian girl who scored a 30 on the TMT-A who has parent(s) with 12 years of education (MLPE). 4) The last step is to use the tables available in most statistical reference books (e.g., Strauss et al., 2006) or use a trusted online calculator like the one available at http://www.measuringu.com/pcalcz/. In the online calculator, you would enter the $\mathrm{z}$ score and choose a one sided test and note the 100-percent of area after hitting the submit button to convert $\mathrm{z}$ scores to percentiles. In this example, the $z$ score (probability) of -0.688 corresponds to the 75th percentile. It is important to remember to use the appropriate tables that correspond to each test (TMT-A and TMT-B) when performing these calculations.

\subsection{User-friendly normative data}

The four-step normative procedures explained above offers the clinician the ability to determine an exact percentile for a child who has a specific score on the TMT. However, this method can be prone to human error due to the number of required computations by hand. To enhance user-friendliness, the authors have completed these steps for a range of raw scores based on age, sex, and MLPE and created tables for clinicians to more easily obtain a percentile range/estimate associated with a given raw score on this test. These tables are available by country and type of test in the Appendix. In order to obtain an approximate percentile for the above example (converting a raw score of 30 seconds on the TMT-A for a Peruvian girl who is 7 years old and whose parent(s) have 12 years of education) using the simplified normative tables provided in the Appendix, the following steps must be followed. (1) First, identify the appropriate table ensuring the appropriate country and test (TMT-A and TMT-B). In this case, the table for TMT-A score for girls from Peru can be found in Table A12. (2) Find the appropriate age of the child, in this case, 7 years old. (3) Next, look in the 7 years' age column to find the approximate location of the raw score obtained on the test. Within the 7 years' column, the score of 30 obtained by this Peruvian girl corresponds to an approximate percentile of 70 .

The percentile obtained using this user-friendly table sometimes could be slightly different than the hand-calculated, more accurate method (75th vs. 70th) because the user-friendly table is based on a limited number of percentile values. Individual percentiles cannot be presented in these tables due to space limitations. If the exact score is not listed in the column, you must estimate the percentile value from the list of raw scores available. 


\section{Discussion}

The TMT is one of the most used neuropsychological tests to evaluate attention, psychomotor speed, visual scanning and sequencing, and mental flexibility (Strauss et al., 2006). Currently, the TMT is one of the most widely used tests in Latin America (ArangoLasprilla et al., 2016) and Spain (Olabarrieta-Landa et al., 2016). Thus, there are norms for adult populations in Latin America (Arango-Lasprilla et al., 2015; Méndez-Ramírez et al., 2015) and Spain (Peña-Casanova et al., 2009; Tamayo et al., 2012).

However, there is a lack of norms for Spanishspeaking children and adolescents. For this reason, the objective of this study was to obtain normative data for the TMT in children and adolescents from nine Latin American countries (Chile, Cuba, Ecuador, Guatemala, Honduras, Mexico, Paraguay, Peru and Puerto Rico) and Spain. The results of the study showed that there are different types of variables associated with the performance of the test such as age, quadratic age, sex, and MLPE. In general, final regression models were found to explain between $11.4 \%$ and $39.4 \%$ of the variance for the total time in the TMT-A, and between $8.9 \%$ and $48.6 \%$ of the variance for the total time in the TMT- B.

Regarding the variables that were associated with test performance, it was found that age was significantly related to total time in the TMT A \& B in all countries, so that the total time to complete the test decreases linearly as children become older. These results are similar with those reported in other studies were the effect of age influenced test performance in children (Beltrán Dulcey \& Solís-Uribe, 2012; Lee et al., 2014; Lee et al., 2002). Additionally, a curvilinear effect was observed for the total time score of the TMT A \& B. In the TMT-A, this curvilinear effect was found for all countries except for Cuba, Guatemala, and Puerto Rico. It was observed that the total time needed to complete TMT-A task decreased sharply until approximately the age of 12 ; however, scores tend to stabilize from this age on, with the exception of Peru and Honduras where scores increased slightly between the ages 13 and 14 . With regards to the TMT-B, the curvilinear effect was found in all countries except Guatemala and Puerto Rico. It was observed that best performance was at 11 and 12 years of age, indicating that less total time is needed to complete the TMT-B task. The total time children need to complete the TMT-B stabilizes at age 12 and 13, with the exception of Cuba, Ecuador,
Honduras, Mexico, Peru, and Spain where time slightly increases.

In this study, the MLPE of the parents was associated with the total time of the TMT A \& B. For the TMT-A, the effect was seen in countries such as Mexico and Paraguay, while for the TMT-B the effect was observed in countries such as Ecuador, Mexico, Paraguay, and Spain. In both cases, children whose parents had $>12$ years of education were found to spend less time on the TMT A \& B than children whose parents had $\leq 12$ years of education. To date, none of the studies in the literature have studied the influence of parents' education on the performance of this test.

Nowadays there is a controversy over whether sex is a variable that influences performance in the TMT. Some studies have found that boys perform better than girls in both versions (Lee et al., 2002), while other studies have found that overall girls perform better in the TMT-B compared to boys (Barr, 2003). However, other studies have found no difference between the sexes (Anderson, Lajoie, \& Bell, 1997; Beltrán Dulcey \& Solís-Uribe, 2012; LeónCarrión, 1989; Mok et al., 2008). In the present study, sex was associated with total time in the TMT-A for Chile, Cuba, Mexico, and Peru so that boys needed less time to complete the test than girls. However, sex was not associated with total time in the TMT-B.

\subsection{Implications}

One of the most worrying aspects in the professional practice of neuropsychology in Latin American countries and Spain is the lack of neuropsychological tests that have been validated and standardized in Spanish (Arango-Lasprilla et al., 2016; Olabarrieta-Landa et al., 2016). For this reason, many neuropsychologist in these countries use norms and tests created in other countries. All this leads to inadequate diagnosis due to socio-demographic and cultural characteristics of the population in which the test is performed. These characteristics are fundamental when interpreting the results (Lezak, 2004; Strauss et al., 2006). Therefore, the results of the present study are very important and will contribute to improve the clinical practice in these countries. This study will allow neuropsychologists to have reliable and valid tools, in addition to normative data by country in order to adequately use in their neuropsychological evaluations of children and adolescents between the ages of 6 and 14 . 


\subsection{Limitations}

Despite the great importance of this study, as it is the largest in the world on validation and standardization of the TMT with Spanish-speaking populations, the results of the study should be interpreted in the light of the following limitations: This study presents normative data for the TMT for nine countries in Latin America and Spain. For this reason, it is not advisable to use these norms in the pediatric population of those Spanish-speaking countries where the study was not performed. Future studies should be conducted to standardize this test in other Spanishspeaking countries.

Although the norms of the present study could be used by neuropsychologists in other countries to evaluate Spanish-speaking immigrant children from the countries where the sample was collected for this study, they should be used with caution since other variables such as level of acculturation, bilingualism, the number of years living in the country, and so on, could influence performance. In addition, the quality of education of both the child and the parent(s) is another aspect that may influence the cognitive performance of children.

It is very important to keep in mind that no clinical diagnosis should be made based solely on the TMT scores. This test should be integrated as part of a much larger battery that evaluates these processes in more detail. Because there are a limited number of tests and norms in Latin America and Spain to evaluate these processes, more efforts should be made in the future to have other similar tools.

Although the size of the sample was adequate in each of the countries where the study was conducted, it is very important to note that only the sample in Chile, Mexico, Paraguay, Puerto Rico, and Spain was obtained from several regions of the country, while in the remaining countries were collected from only one geographic area. Future studies should expand the sample in other geographical areas of these countries with the objective to be able to have a greater representativeness of the sample.

The children who participated part in the present study had Spanish as their first language. Although Spanish is the first language of the majority of the population in Latin America and Spain, it is important to keep in mind there is a great cultural and linguistic richness to the point that in many of these countries, sometimes the first language of many children may be completely different from Spanish (e.g., Portuguese, Euskera, Catalan, Guaraní, Maya, Quechua).
For this reason, caution should be used when using these norms in children whose first language is not Spanish.

Finally, it is important to keep in mind that the present study was performed with normal healthy population. Therefore, future studies should be performed with clinical population to establish the sensitivity and specificity of this test.

\subsection{Conclusions}

The TMT is one of the neuropsychological tests currently used to evaluate attention, psychomotor speed, visual scanning and sequencing, and mental flexibility in children and adolescents in Latin America and Spain. In this study, it was found that older age, higher parental education level and sex influences TMT scores. This is the first study to develop norms for children and adolescents between the ages 6 and 14 for nine countries from Latin America and Spain. The results of this study are expected to contribute to the improvement of quality standards in the neuropsychological evaluation of pediatric population in these countries.

\section{Conflict of interest}

None to report.

\section{Supplementary material}

The Appendix tables are available in the electronic version of this article: http://dx.doi.org/10. 3233/NRE-172247.

\section{References}

Abe, M., Suzuki, K., Okada, K., Miura, R., Fujii, T., Etsurou, M., \& Yamadori, A. (2004). [Normative data on tests for frontal lobe functions: Trail Making Test, Verbal fluency, Wisconsin Card Sorting Test (Keio version)]. Brain and Nerve, 56(7), 567-574.

Adjutant General Office, Classification and Replacement Branch, Personnel Research Section. (1944). The new Army individual test of general ability. Psychological Bulletin, 41, 532-538.

Aiken, L. S., \& West, S. G. (1991). Multiple regression: Testing and interpreting interactions. Newbury Park, CA: Sage.

Anderson, P. (2002). Assessment and development of executive function (EF) during childhood. Child Neuropsychology, 8(2), 71-82.

Anderson, V., Lajoie, G., \& Bell, R. (1997). Neuropsychology assessment of the school-aged child. Department of Psychology, Royal Children's Hospital, Melbourne, Australia. 
Arango-Lasprilla, J. C., Olabarrieta Landa, L., Rivera, D., Olivera Plaza, S. L., De los Reyes Aragón, C. J., Calderón Chagualá, J. A., \& Quijano, M. C. (2015a). Situación actual de la neuropsicología en Colombia [Current status of neuropsychology in Colombia]. In J. C. Arango-Lasprilla, \& D. Rivera (Eds.), Neuropsicología en Colombia: Datos normativos, estado actual $y$ retos a futuro [Neuropsychology in Colombia: Normative data, current state, and challenges for the future] (pp. 21-46). Manizales: Editorial Universidad Autónoma de Manizales.

Arango-Lasprilla, J. C., Rivera, D., Aguayo, A., Rodríguez, W., Garza, M. T., Saracho, C. P., ...\& Longoni, M. (2015b). Trail making test: Normative data for the Latin American Spanish speaking adult population. NeuroRehabilitation, 37(4), 639661.

Arango-Lasprilla, J. C., Stevens, L., Morlett-Paredes, A., Ardila, A. \& Rivera, D. (2016). Profession of neuropsychology in Latin America. Applied neuropsychology: Adult, 24(4), 318330. doi: 10.1080/23279095.2016.1185423

Barr, W. B. (2003). Neuropsychological testing of high school athletes:Preliminary norms and test-retest indices. Archives of Clinical Neuropsychology, 18, 91-101.

Beltrán Dulcey, C., \& Solís-Uribe, G. (2012). Evaluación Neuropsicológica en adolescentes: Normas para población de Bucaramanga. Revista Neuropsicología, Neuropsiquiatría y Neurociencias, 12(2), 77-93.

Bezdicek, O., Motak, L., Axelrod, B. N., Preiss, M., Nikolai, T., Vyhnalek, M., ...\& Ruzicka, E. (2012). Czech version of the Trail Making Test: Normative data and clinical utility. Archives of Clinical Neuropsychology, 27(8), 906-914.

Blanco-Gómez, A., Ferré, N., Luque, V., Cardona, M., GispertLlauradó, M., Escribano, J., ...\& Canals-Sans, J. (2015). Being overweight or obese is associated with inhibition control in children from six to ten years of age. Acta Paediatrica, 104(6), 619-625.

Brown, L., Sherbenou, R. J. \& Johnsen, S. K. (2009). Test de inteligencia no verbal TONI-2. Madrid: TEA ediciones.

Cangoz, B., Karakoc, E., \& Selekler, K. (2009). Trail Making Test: Normative data for Turkish elderly population by age, sex and education. Journal of the Neurological Sciences, 283(1), 73-78.

Cavaco, S., Gonçalves, A., Pinto, C., Almeida, E., Gomes, F., Moreira, I., ...\& Teixeira-Pinto, A. (2013). Trail Making Test: Regression-based norms for the Portuguese population. Archives of Clinical Neuropsychology, 28, 189-198.

Cook, R. D. (1977). Detection of influential observation in linear regression. Technometrics, 19(1), 15-18. doi: $10.2307 / 1268249$

Egeland, J., Lovstad, M., Norup, A., Nybo, T., Persson, B. A., Rivera, D. F., Schanke, A. K., Sigurdardottir, S., \& ArangoLasprilla, J. C. (2016). Following international trends while subject to past traditions: Neuropsychological test use in the Nordic countries. Clinical Neuropsychologist, 30(Sup1), 14791500 .

Espy, K. A., \& Cwik, M. F. (2004). The development of a trial making test in young children: The TRAILS-P. The Clinical Neuropsychologist, 18(3), 411-422.

Fernández, A., Ferreres, A., Morlett-Paredes, A., Rivera, D., \& Arango-Lasprilla, J. C. (2016). Past, present, and future of neuropsychology in Argentina. Clinical Neuropsychologist, 30(8), 1154-1178.

Fernández, A., Marino, J. \& Alderete, A. (2002). Estandarización y validez conceptual del Test del Trazo en una muestra de adultos argentinos [Normative data and conceptual validity of the
Trail Making Test in a sample of Argentinean adults]. Revista Neurológica Argentina, 27(2), 83-88.

Hashimoto, R., Meguro, K., Lee, E., Kasai, M., Ishii, H., \& Yamaguchi, S. (2006). Effect of age and education on the Trail Making Test and determination of normative data for Japanese elderly people: The Tajiri Project. Psychiatry and Clinical Neurosciences, 60(4), 422-428.

Kovacs, M. (1992). Children's depression inventory. North Tonawanda, NY: Multi-Health System.

Kutner, M. H., Nachtsheim, C. J., Neter, J., \& Li, W. (2005). Applied linear statistical models (5th ed.). New York: McGraw Hill.

Lee, N. R., Wallace, G. L., Raznahan, A., Clasen, L. S., \& Giedd, J. N. (2014). Trail making test performance in youth varies as a function of anatomical coupling between the prefrontal cortex and distributed cortical regions. Frontiers in Psychology, 5.

Lee, T. M., Yuen, K. S., \& Chan, C. C. (2002). Normative data for neuropsychological measures of fluency, attention, and memory measures for Hong Kong Chinese. Journal of Clinical and Experimental Neuropsychology, 24(5), 615-632.

León-Carrión, J. (1989). Trail making test scores for normal children: Normative data from Spain. Perceptual and Motor Skills, 68, pp. 627-630.

Lezak, M. (1995). Neuropsychological assessment. Vol. 3. New York: Oxford University Press.

Lezak, M. D. (2004). Neuropsychological assessment. New York: Oxford University Press.

Llorente, A. M. (2003). Children's color trails test: Professional manual. Psychological Assessment Resources.

Mateo, V. F. (2010). Neuropsicología infantil: Intento de validación del trail-making test en población escolar no patológica. Quaderns digitals: Revista de Nuevas Tecnologías y Sociedad, (65), 17.

Méndez-Ramirez, L. F., Rivera, D., Quijano, M. C., Calderon Chagualá, J. A., De los Reyes Aragón, C. J., Olivera Plaza, S. L., ..., \& Arango-Lasprilla, J. C., (2015). Datos normativos del test Copia y reproducción de Memoria de la figura Geométrica compleja de Rey para población Colombiana. In J. C. Arango-Lasprilla, \& D. Rivera (Eds.), Neuropsicología en Colombia: Datos normativos, estado actual y retos a futuro [Neuropsychology in Colombia: Normative data, current state, and challenges for the future] (pp. 81-98). Manizales: Editorial Universidad Autónoma de Manizales.

Mok, N., Tsang, L., Lee, T. M., \& Llorente, A. M. (2008). The impact of language on the equivalence of trail making tests: Findings from three pediatric cohorts with different language dominance. Applied Neuropsychology, 15(2), 123-130.

Närhi, V., Räsänen, P., Metsäpelto, R. L., \& Ahonen, T. (1997). Trail Making Test in assessing children with reading disabilities: A test of executive functions or content information. Perceptual and Motor Skills, 84(3 suppl), 1355-1362.

Olabarrieta-Landa, L., Caracuel, A., Pérez-García, M., Panyavin, I., Morlett-Paredes, A., \& Arango-Lasprilla, J. C. (2016). The profession of neuropsychology in Spain: Results of a national survey. The Clinical Neuropsychologist, 30(8), 1335-1355.

Partington, J., \& Leiter, R. (1949). Partington's pathways test. Psychological Service Center Bulletin, 1, 11-20.

Peña-Casanova, J., Quiñones-Úbeda, S., Quintana-Aparicio, M., Aguilar, M., Badenes, D., Molinuevo, J. L., et al., \& NEURONORMAStudyTeam. (2009). Spanish Multicenter Normative Studies (NEURONORMA Project): Norms for verbal span, visuospatial span, letter and number sequencing, trail 
making test, and symbol digit modalities test. Archives of Clinical Neuropsychology, 24(4), 321-341.

Periáñez, J. A., Rios-Lago, M., Rodriguez-Sanchez, J. M., Adrover-Roig, D., Sanchez-Cubillo, I., Crespo-Facorro, B. E. E. A., ...\& Barcelo, F. (2007). Trail Making Test in traumatic brain injury, schizophrenia, and normal ageing: Sample comparisons and normative data. Archives of Clinical Neuropsychology, 22(4), 433-447.

Rabin, L. A., Barr, W. B., \& Burton, L. A. (2005). Assessment practices of clinical neuropsychologists in the United States and Canada: A survey of INS, NAN, and APA Division 40 members. Archives of Clinical Neuropsychology, 20, 33-65.

Reitan, R. M. (1958). The validity of the Trail Making Test as an indicator of organic brain damage. Perceptual and Motor Skills, 8, 271-276.

Reitan, R. M. (1979). Manual for administration of neuropsychological test batteries for adults and children. Tucson, AZ: Reitan Neuropsychological Laboratory.

Reitan, R. M. (1992). Trail Making Test: Manual for Administration and Scoring. Tucson, AZ: Reitan Neuropsychology Laboratory.

Reitan, R. M., \& Boll, T. J. (1973). Neuropsychological correlates of minimal brain dysfunction. In Annals of the New York Academy of Sciences, Conference on Minimal Brain Dysfunction (pp. 65-88). New York: New York Academy of Sciences.

Reitan, R. M., \& Wolfson, D. (1988). Neuropsychological functions of learning-disabled, brain-damaged, and normal children. The Clinical Neuropsychologist, 2, 278.

Reitan, R. M., \& Wolfson, D. (1992). Neuropsychological evaluation of older children. Tucson, AZ: Neuropsychology Press.

Reynolds, C. R. (2002). Comprehensive Trail Making Test $(C T M T)$. Austin, TX: PRO-ED, Inc.

Rivera, D., \& Arango-Lasprilla, J. C. (2017). Methodology for the development of normative data for Spanish Speaking pediatric population. NeuroRehabilitation, 41(3), 581-592.

Sanchez-Cubillo, I., Periañez, J. A., Adrover-Roig, D., RodriguezSanchez, J. M., Rios-Lago, M., Tirapu, J., \& Barcelo, F. (2009). Construct validity of the Trail Making Test: Role of taskswitching, working memory, inhibition/interference control, and visuomotor abilities. Journal of the International Neuropsychological Society, 15(03), 438-450.

Seo, E. H., Lee, D. Y., Kim, K. W., Lee, J. H., Jhoo, J. H., Youn, J. C., .. \& \& Woo, J. I. (2006). A normative study of the Trail Making Test in Korean elders. International Journal of Geriatric Psychiatry, 21(9), 844-852.

Strauss, E., Sherman, E. M., \& Spreen, O. (2006). A compendium of neuropsychological tests: Administration, norms, and commentary. American Chemical Society.

Tamayo, F., Casals-Coll, M., Sánchez-Benavides, G., Quintana, M., Manero, R. M., Rognoni, T., ...\& Peña-Casanova, J. (2012). Estudios normativos españoles en población adulta joven (Proyecto NEURONORMA jóvenes): Normas para las pruebas span verbal, span visuoespacial, Letter-Number Sequencing, Trail Making Test y Symbol Digit Modalities Test. Neurologia, 27(6), 319-329.

Tombaugh, T. N. (2004). Trail Making Test A and B: Normative data stratified by age and education. Archives of Clinical Neuropsychology, 19(2), 203-214.

Van der Elst, W., Hurks, P., Wassenberg, R., Meijs, C., \& Jolles, J. (2011). Animal Verbal Fluency and Design Fluency in schoolaged children: Effects of age, sex, and mean level of parental education, and regression-based normative data. Journal of Clinical \& Experimental Neuropsychology, 33(9), 1005-1015.

Wang, Q., Sun, J., Ma, X., Wang, Y., Yao, J., Deng, W., Liu, X., Collier, D., \& Li, T. (2011). Normative data on a battery of neuropsychological tests in the Han Chinese population. Journal of Neuropsychology, 5(1), 126-142.

Williams, J., Rickert, V., Hogan, J., Zolten, A. J., Satz, P., D’Elia, L. F., .. \& \& Light, R. (1995). Children's color trails. Archives of Clinical Neuropsychology, 10(3), 211-223.

Zalonis, I., Kararizou, E., Triantafyllou, N. I., Kapaki, E., Papageorgiou, S., Sgouropoulos, P. E. E. A., \& Vassilopoulos, D. (2008). A normative study of the trail making test A and B in Greek adults. The Clinical Neuropsychologist, 22(5), 842-850. 